\title{
Low-frequency pulse plating for tailoring the optical appearance of chromium layers for decorative applications
}

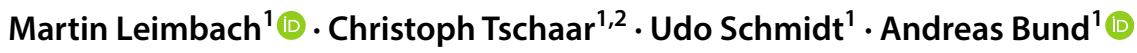

Received: 19 September 2019 / Accepted: 3 February 2020 / Published online: 21 February 2020

(c) The Author(s) 2020

\begin{abstract}
The optical appearance of electroplated chromium layers is a crucial factor for decorative applications. Currently in the decorative chromium plating industry the so far used hexavalent electrolytes are being replaced progressively by solutions of trivalent chromium. However, chromium deposited from trivalent baths tends to have a yellowish color hue at thicknesses beyond $100 \mathrm{~nm}$, which is undesired for most applications. The shift in color is related to a change in surface morphology due to the globular growth of the chromium nuclei. By utilizing pulsed current with on-times in the range of seconds, the grain growth is suppressed and the formation of fresh nuclei is favored. As a result, the average grain size of the layer can be decreased significantly. Compact chromium layers with small grains and improved color values are formed. A blueish appearance and high brightness were maintained up to thicknesses of more than $200 \mathrm{~nm}$. Based on the results a combination of constant and pulsed current is suggested, yielding similar visual appearance as in the case of pulsed current only, but reaching the targeted film thickness much faster.
\end{abstract}

\section{Graphic abstract}

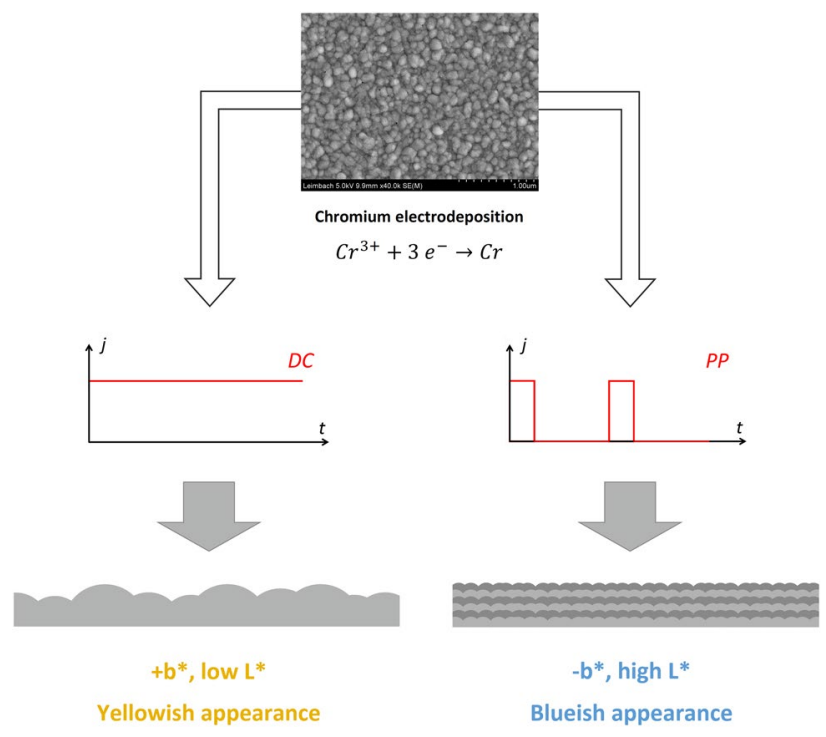

Keywords Chromium electrodeposition $\cdot$ Trivalent chromium electrolyte $\cdot$ Surface morphology $\cdot$ Optical appearance $\cdot$ Nucleation and growth $\cdot$ Pulse plating

Martin Leimbach

martin.leimbach@tu-ilmenau.de

Extended author information available on the last page of the article 


\section{Introduction}

Electrodeposition of chromium for decorative applications plays a prominent role in the surface finishing industry, especially in sanitary, automotive, shopfitting, housewares, plating on plastics and similar fields [1]. In these applications, chromium layers are usually several hundreds of nanometers thick and provide a high level of brightness and corrosion resistance in combination with the underlying layers of bright or semi-bright nickel [2]. Processes based on chromic acid electrolytes have been state of the art in decorative chromium plating for many decades [3]. However, the use of hexavalent chromium compounds is more and more restricted due to their toxicity and carcinogenicity $[4,5]$. Thus, solutions of trivalent chromium salts have been introduced to industry around 1970 as a less harmful alternative to chromic acid electrolytes [6]. The reduction of trivalent chromium takes place via two steps (Eqs. 1, 2).

$\mathrm{Cr}^{3+}+\mathrm{e}^{-} \rightarrow \mathrm{Cr}^{2+}$

$\mathrm{Cr}^{2+}+2 \mathrm{e}^{-} \rightarrow \mathrm{Cr}^{0}$

Usually organic additives are added to the bath to increase the efficiency of reaction (2) [7, 8]. Today there is a broad variety of commercially available trivalent chromium baths in Europe, North America and East Asia [9]. On the other hand, commercially applicable processes based on trivalent chromium cannot fully meet the requirements in terms of optical appearance. While chromium deposits from a hexavalent bath exhibit a blueish color appearance, a slight yellow or dark hue is characteristic for chromium layers plated from most trivalent chromium based electrolytes [10]. In addition, the reproducibility of a specific color is poorer. This is clearly due to a lack of fundamental understanding of the influencing factors on optical appearance. Besides aesthetic considerations, these aspects are crucial if chromium-plated parts form different suppliers are installed side by side. The aim is to achieve a process-stable hue in the blue range of the color spectrum, as close as possible to the appearance of parts from hexavalent baths. The latter are still considered as benchmarks in decorative chromium plating [11].

In our previous paper [12], we showed that the color of chromium with a small amount of impurities depends on surface morphology. In the case of a trivalent chromium electrolyte, grain size and roughness increase during layer growth, causing a color shift from blueish at very low thickness to yellowish at thicknesses beyond $100 \mathrm{~nm}$. In contrast, surface morphology and visual appearance remain nearly constant in the case of hexavalent electrolytes. To achieve a blueish appearance for a trivalent based system while having a sufficient protection ability of the coating, a fined-grained surface structure has to be realized for layers thicknesses of several hundred nm. By application of pulsed instead of constant cathodic current, the grain growth can be suppressed due to the periodic interruption of the deposition process [13]. With the beginning of each current pulse, the formation of fresh nuclei starts again.

Pulse and pulse reverse plating have been applied for both hexavalent [14-16] and trivalent [17-19] based systems, mostly at frequencies between $10 \mathrm{~Hz}$ and $10 \mathrm{kHz}$. An increased current efficiency of chromium deposition was observed and has been explained with the removal of adsorbed hydrogen during off-times and the replenishment of chromium ions at the electrode surface [20]. Furthermore, grain structure and texture formation were affected, leading to improved mechanical properties [21] and better corrosion resistance [22]. These approaches were focusing on producing thick chromium layers for functional applications. They placed less emphasis on the optical appearance. For tailoring the color of the chromium surface by refining the surface morphology at the nanometer scale, pulse duration and off-times in the range of seconds appear to be more favorable [23]. This corresponds to very low frequencies $(<1 \mathrm{~Hz})$. A recent approach discusses the application of low-frequency pulse plating to reduce the internal stress of chromium deposits [24, 25].

Pulse plating is a powerful technique in which the current can be modified over a wide range via various parameters. In this work, two different pulse regimes were chosen for the electrodeposition of chromium from a trivalent electrolyte. The results will be compared with samples plated at constant current from the same solution. Color values were measured and SEM pictures were taken to assess the optical appearance and morphological characteristics of the deposits. Different stages of layer growth were observed for the lowfrequency pulse regime, so that conclusions on chromium nucleation and growth can be drawn. The findings from our previous paper on color-morphology relations of chromium [12] were taken as a basis for the interpretation of the results.

\section{Experimental}

\subsection{Sample preparation}

Polished brass panels (size $5 \times 7.5 \mathrm{~cm}^{2}$ ) were used as substrates. The panels were degreased with a commercial alkaline electrolytic cleaner (HSO Uni 1, Herbert Schmidt GmbH Solingen, Germany) applying a cathodic current density of $2 \mathrm{~A} \mathrm{dm}^{-2}$ for $4 \mathrm{~min}$. Stainless steel served as anode material. After degreasing, the samples were dipped in $10 \mathrm{vol} \%$ sulfuric acid for activation and plated with $10 \mu \mathrm{m}$ of nickel from a commercial bright nickel electrolyte [26] 
Table 1 Composition of the bright nickel electrolyte ORION 4000 provided by Kiesow Dr. Brinkmann GmbH \& Co. KG [26]

\begin{tabular}{ll}
\hline Component & Concentration \\
\hline $\mathrm{Ni}^{2+}$ & $75 \mathrm{~g} \mathrm{l}^{-1}\left(1.3 \mathrm{~mol} \mathrm{l}^{-1}\right)$ \\
$\mathrm{Cl}^{-}$ & $18 \mathrm{~g} \mathrm{l}^{-1}\left(0.5 \mathrm{~mol} \mathrm{l}^{-1}\right)$ \\
$\mathrm{H}_{3} \mathrm{BO}_{3}$ & $40 \mathrm{~g} \mathrm{l}^{-1}\left(0.6 \mathrm{~mol} \mathrm{l}^{-1}\right)$ \\
$\mathrm{Nickel} \mathrm{additive} \mathrm{520}^{-1}$ & $15 \mathrm{ml} \mathrm{l}^{-1}$ \\
Nickel additive TR A & $3 \mathrm{ml} \mathrm{l}^{-1}$ \\
$\mathrm{pH}$ & 4.4 \\
Temperature & $55^{\circ} \mathrm{C}$ \\
\hline
\end{tabular}

(Table 1). Sulfur-depolarized nickel plates were used as anodes.

The deposition of chromium was carried out in a commercial chromium(III)-sulfate based electrolyte (SAPHIR 2000 provided by Kiesow Dr. Brinkmann GmbH \& Co. KG, Germany) at $\mathrm{pH} 3.2$ and $55^{\circ} \mathrm{C}$ [27]. Two liters of electrolyte were used in a beaker with two parallel mixed metal oxide anodes (De Nora GreenChrome ${ }^{\circledR}$ ). During the plating, the samples were moved parallel to the anodes in an alternate motion at a velocity of $6 \mathrm{~cm} \mathrm{~s}^{-1}$ in order to support the removal of hydrogen bubbles from the surface and facilitate mass transport. The same setup was used for both constant and pulsed current plating experiments. A BioLogic SP-150 potentiostat with VMP3B-20 (20A/20 V) booster was used for the pulse plating experiments.

The constant current (DC) plated samples were prepared at $5 \mathrm{~A} \mathrm{dm}^{-2}$ and characterized by colorimetry. In accordance to the practically applicable thickness range of decorative chromium layers [2], about $500 \mathrm{~nm}$ was chosen as the maximum plating thickness with equidistant intermediate steps. The plating time was varied from 1 to $14 \mathrm{~min}$, corresponding to layer thicknesses of 40 and $550 \mathrm{~nm}$, respectively. Pulse plating experiments were performed with a peak current density of $5 \mathrm{~A} \mathrm{dm}^{-2}$. At higher current densities, the efficiency of chromium deposition decreases rapidly due to the formation of chromium hydroxides near the electrode surface, so that any further increase of the peak current density is detrimental [28]. Two different pulse periods were used. Firstly, a frequency of $1 \mathrm{~Hz}$ with an on-time of 0.5 and an off-time of $0.5 \mathrm{~s}$ was applied. The duration of the plating was $14 \mathrm{~min}$. Secondly, low-frequency pulse plating was done with an on-time of $15 \mathrm{~s}$ and an off-time of $22.5 \mathrm{~s}$. The deposition time was varied from $37.5 \mathrm{~s}$ (one pulse) to $15 \mathrm{~min}$ and $37.5 \mathrm{~s}$ ( 25 pulses). One sample was prepared for each condition.

\subsection{Characterization of the deposits}

For the color measurements, the recommendations of the International Commission on Illumination (CIE) for colorimetry [29] were followed. The samples were irradiated by visible light with a D65 standardized spectrum. The spectrum of the reflected light was detected under an angle of $8^{\circ}$ to normal. Both the specular and the diffuse reflected light were considered for analysis. A spectral photometer CM-700d from KONICA MINOLTA with a spot size of $6 \mathrm{~mm}$ was used. From the collected spectral data, the color values in the $L^{*} a^{*} b^{*}$ system were derived according to ASTM guidelines [30]. Twelve positions on one sample for each condition were measured and the average values for each sample were calculated.

The thickness of the chromium layers was determined by $\mathrm{X}$-ray fluorescence spectroscopy (XRF) using a Fischerscope $\mathrm{XDV}$ at a voltage of $50 \mathrm{kV}$, spot size of $3 \mathrm{~mm}$ and measuring time of $30 \mathrm{~s}$ per position. The same specimen as used for colorimetry was characterized. Thickness values were collected for each sample from nine positions distributed uniformly over the surface and the average value was calculated. Scanning electron microscopy (SEM) and electron dispersive X-ray spectroscopy (EDS) were carried out with a SEM Hitachi S4800 with secondary electron detector at an acceleration voltage of $5 \mathrm{kV}$ and $10 \mathrm{kV}$, respectively. A section with an area of about one square centimeter was cut from each sample for transfer into the electron microscope. Grain size and pore diameter were evaluated from the micrographs.

\section{Results and discussion}

\subsection{Constant current (DC) plating}

$L^{*}, a^{*}$ and $b^{*}$ color values of the DC-plated samples are plotted versus thickness in Fig. 1. The $L^{*}$ parameter indicates the lightness in a range from 0 (black) to 100 (white). $a^{*}$ and $b^{*}$ represent the directions of color hue, with positive $a^{*}$ as red, negative $a^{*}$ as green, positive $b^{*}$ as yellow and negative $b^{*}$ as blue direction. Colorlessness corresponds to $a^{*}=b^{*}=0$. A linear fit was made for each parameter to reveal tendencies in the data (Table 2). The relation between color and thickness is qualitatively the same as already discussed previously [12], i. e. decreasing $L^{*}$ and increasing $b^{*}$ with increasing thickness. $a^{*}$ depends only weakly on thickness, as is apparent from the low correlation coefficient $\left(R^{2}=0.05\right)$. Standard deviations are in the expected range for colorimetry of electroplated chromium layers [10, 12]. A blueish appearance can be achieved by DC plating only for layer thicknesses below $100 \mathrm{~nm}$, which is unsuitable for most decorative applications.

The shift in $L^{*}$ and $b^{*}$ is caused by a coarsening of the surface structure during layer growth, leading to an increase of grain size and roughness. As can be seen from the SEM images (Fig. 2), the average grain size increases from 

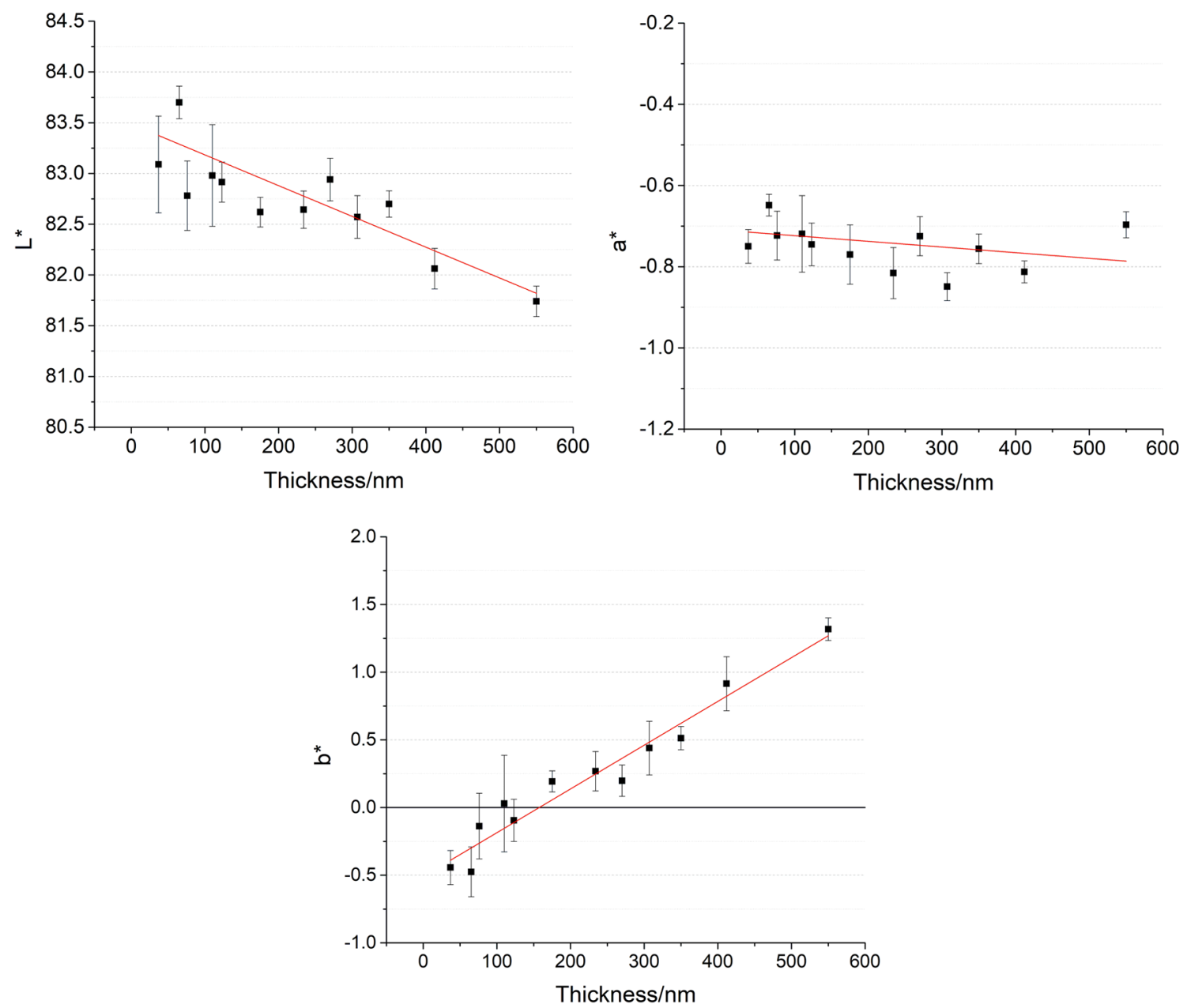

Fig. 1 Plots of the color values $L^{*}, a^{*}$ and $b^{*}$ versus the thickness of chromium layers electroplated at constant current with a current density of $5 \mathrm{~A} \mathrm{dm}^{-2}$. The trend lines of the linear fit are indicated to expose linear dependencies between color values and thickness

Table 2 Linear fit data corresponding to the plots of the color values $L^{*}, a^{*}$ and $b^{*}$ versus the thickness of chromium layers electroplated at constant current with a current density of $5 \mathrm{~A} \mathrm{dm}^{-2}$ (Fig. 1)

\begin{tabular}{lccc}
\hline Plot & \multicolumn{2}{l}{ Linear fit $y=a \times+b$} & \\
\cline { 2 - 4 } & $a$ & $b$ & $R^{2}$ \\
\hline$L^{*}$ versus thickness & $-0.0030 \pm 0.0005$ & $83.5 \pm 0.2$ & 0.73 \\
$a^{*}$ versus thickness & $0.00014 \pm 0.00011$ & $-0.71 \pm 0.04$ & 0.05 \\
$b^{*}$ versus thickness & $0.0032 \pm 0.0002$ & $-0.51 \pm 0.07$ & 0.96 \\
\hline
\end{tabular}

approximately $40 \mathrm{~nm}$ at a thickness of $40 \mathrm{~nm}$ to $250 \mathrm{~nm}$ at a thickness of $550 \mathrm{~nm}$. Furthermore, the grain size distribution becomes broader, leading to a more heterogeneous structure. Pores with a diameter of about 20 to $40 \mathrm{~nm}$ can be found in all samples due to simultaneous hydrogen evolution during chromium plating. The EDS analysis of the sample with a thickness of $550 \mathrm{~nm}$ (Table 3) reveals small amounts of impurities. Sulfur (approx. $2 \mathrm{wt} \%$ ) and carbon (approx. $1 \mathrm{wt} \%$ ) are incorporated due to organic additives in the electrolyte, while oxygen (approx. $1 \mathrm{wt} \%$ ) originates from the formation of oxides once the sample comes into contact with air. As the electrolyte composition was kept constant for all experiments, a similar chemical composition can be assumed for all samples. The impurities in the layers may have a slight effect on their optical appearance, but this is superimposed by morphological effects.

\subsection{Pulse plating at $1 \mathrm{~Hz}$}

First pulse deposition experiments were done at a frequency of $1 \mathrm{~Hz}$ with an on-time and off-time of $0.5 \mathrm{~s}$ each. This equals to a duty cycle of $50 \%$. The relation between the pulse duration is given by Eqs. 3 and 4 .

$f=1 / T=1 /\left(t_{\text {on }}+t_{\text {off }}\right)$ 

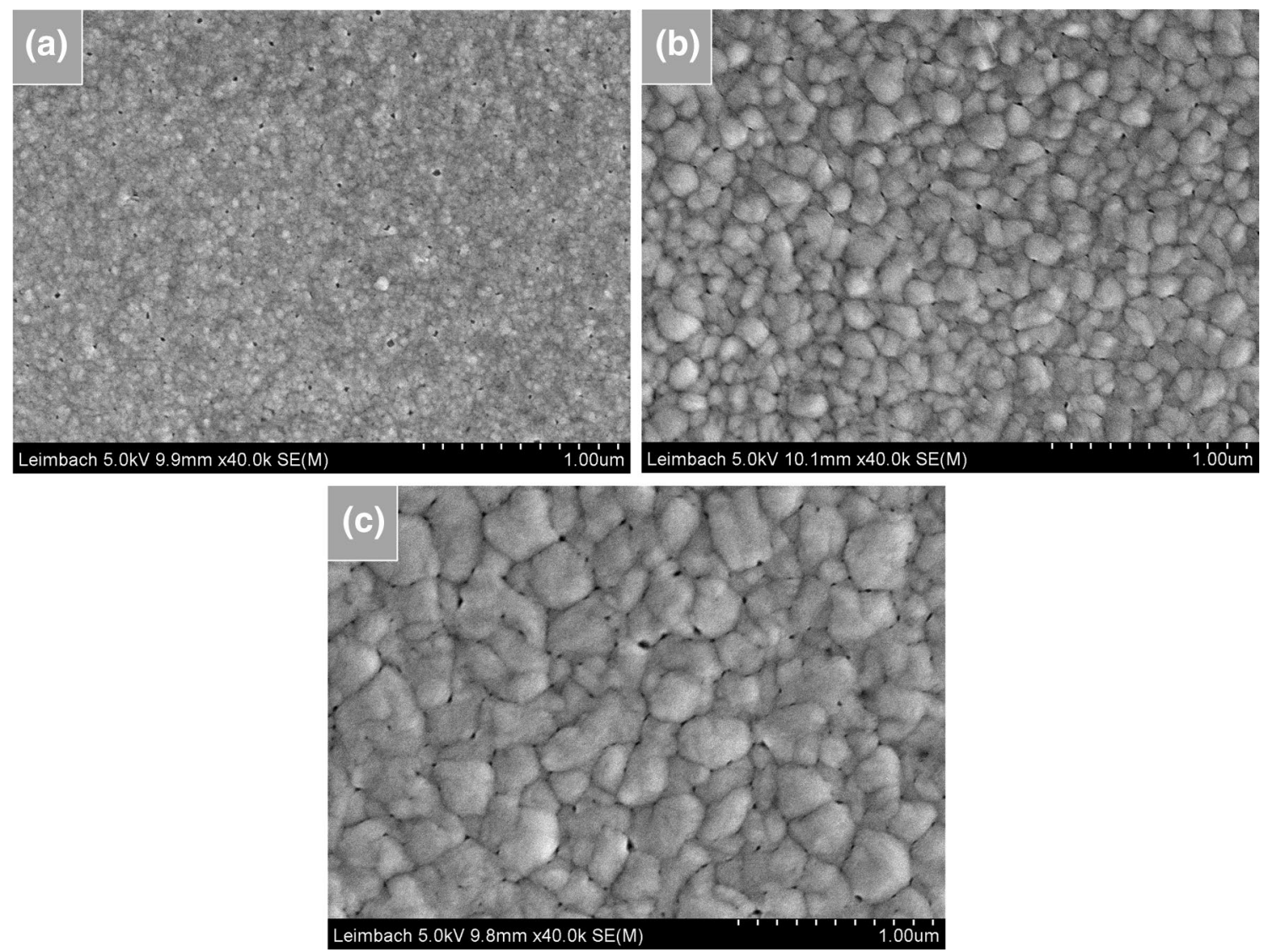

Fig. 2 SEM images of chromium layers electroplated at constant current with a current density of $5 \mathrm{~A} \mathrm{dm}^{-2}$. The average layer thickness is a $40 \mathrm{~nm}, \mathbf{b} 230 \mathrm{~nm}$ and c $550 \mathrm{~nm}$, respectively

Table 3 Chemical composition (determined by EDS) of a chromium layer electroplated at constant current with a current density of $5 \mathrm{~A} \mathrm{dm}^{-2}$

$\Theta=t_{\mathrm{on}} / T=t_{\mathrm{on}} * f$.

In Eqs. 1 and 2, $f$ is the frequency, $T$ the period, $t_{\text {on }}$ the on-time, $t_{\text {off }}$ the off-time, and $\Theta$ the duty cycle. An average chromium thickness of $290 \mathrm{~nm}$ was deposited. The surface morphology of the deposit (Fig. 3) is very different from DC-plated chromium layers. Instead of a globular-like structure, the grains have a triangular or polygonal shape with sizes between 50 and $150 \mathrm{~nm}$. However, the grain boundaries are much harder to distinguish compared to DC plating. In

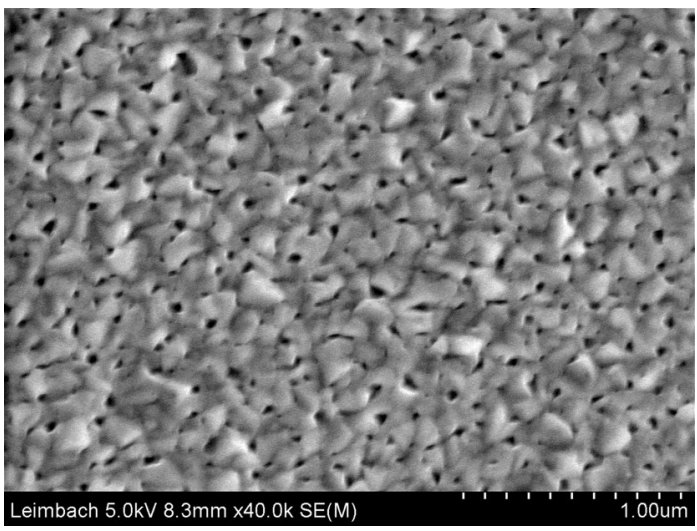

Fig. 3 SEM image of a chromium layer electroplated at pulsed current with a peak current density of $5 \mathrm{~A} \mathrm{dm}^{-2}$, a frequency of $1 \mathrm{~Hz}$ and a duty cycle of $50 \%$

addition, density and diameter of the pores are way higher for the pulse plated than for the DC-plated samples. Such a high porosity degrades the corrosion resistance as well as the visual appearance of the chromium layer. In comparison 
Fig. 4 Schematic representation of the chromium layer growth during electrodeposition. $\mathbf{a}-\mathbf{c}$ indicate the early stages of layer formation, $\mathbf{d}$ the further growth at constant current and e the layer-by-layer growth at low-frequency pulsed current, respectively (a)

(b)

(c)

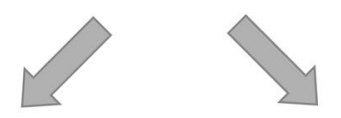

(d)

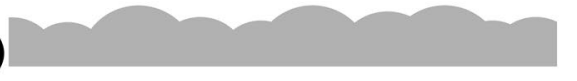

(e)

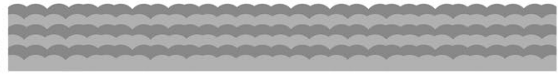

to the color values of a DC-plated layer with the same thickness taken from Fig. 1, $L^{*}$ is decreased from approximately 82.5 to 79.9 and $b^{*}$ is increased from +0.5 to +1.6 , giving a darker and more yellowish color hue.

\subsection{Chromium layer growth}

The reason for the formation of the structures discussed above lies in the formation and growth of chromium nuclei during electrodeposition. Figure 4 is a schematic sketch of the formation of a chromium deposit on a smooth metal substrate electroplated in a trivalent chromium electrolyte. In the initial stage, a high number of chromium nuclei are formed at the electrode surface (Fig. 4a). With increasing plating time, the nucleation rate decreases while the growth of the nuclei proceeds, leading to a globular-like type of growth (Fig. 4b). Several seconds are needed to form a compact layer given the low deposition rate of chromium (Fig. 4c). In the case of pulse plating at frequencies of $1 \mathrm{~Hz}$ and higher, the growth is stopped in an early stage well before a compact layer is formed, resulting in a polygonal morphology with the high porosity that is visible in Fig. 3. At very high frequencies, double layer charge and discharge processes also affect the deposition process as they can distort the current waveform [13]. Hence, the deposition of a compact layer of chromium during one current pulse appears to be beneficial for the surface properties of the coating. Consequently an on-time of several seconds is needed.

If the metal growth proceeds constantly after forming a compact layer, the concentration gradients around the nuclei will overlap, so that some nuclei will grow at the expense of others (Fig. 4d). This leads to an increase of grain size and roughness and, therefore, a shift in color. Such effects take place with DC plating. In contrast, if the current is interrupted, the concentration gradients relax, the nucleation will be re-initiated as soon as the current is turned on again and the process of formation and growth would start over. The applied current regime would equal pulse plating with frequencies far below $1 \mathrm{~Hz}$. Assuming that the nucleation mechanism is reproducible at every current pulse, a layer-by-layer structure would form (Fig. 4e). As each sublayer would have similar surface characteristics, morphologies of the final surface and a single sub-layer should be comparable. Or in other words, the optical appearance of the final deposit should be similar to one individual layer.

\subsection{Low-frequency pulse plating}

As a proof of concept, low-frequency pulse plating was done with an on-time of $15 \mathrm{~s}$ and an off-time of $22.5 \mathrm{~s}$, giving a frequency of $0.027 \mathrm{~Hz}$ and a duty cycle of $40 \%$. The peak current density was kept at $5 \mathrm{~A} \mathrm{dm}^{-2}$. The total deposition time, i. e. the number of pulses, was varied and color values and thickness were measured afterwards. For the lowfrequency pulse plating, the deposition time is referred as the number of pulses as this notation is more suitable to represent the number of deposited sub-layers. The thickness increases linearly with the number of pulses (Fig. 5), which is in accordance with the proposed model. As in the case

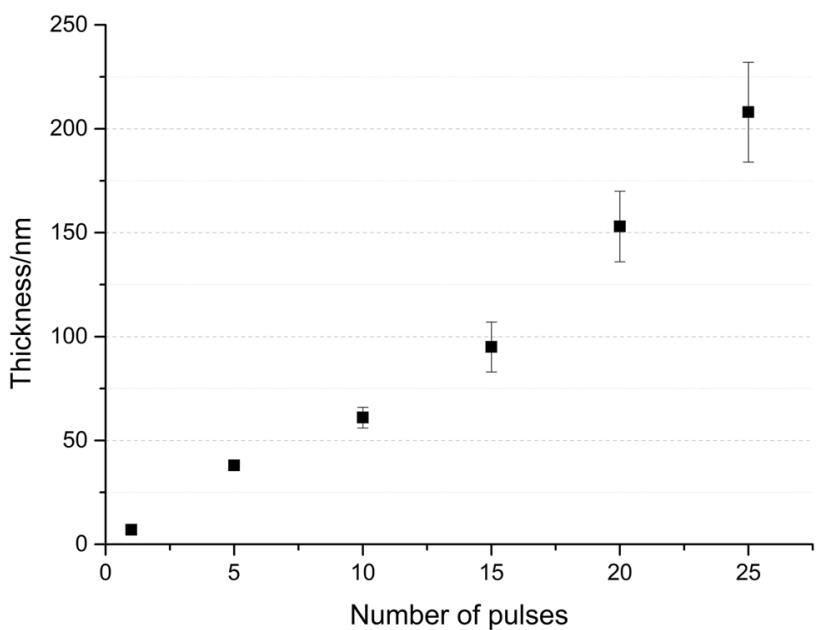

Fig. 5 Plot of the layer thickness versus the number of pulses for chromium layers electroplated at pulsed current with a peak current density of $5 \mathrm{~A} \mathrm{dm}^{-2}$, a frequency of $0.027 \mathrm{~Hz}$ and a duty cycle of $40 \%$ 

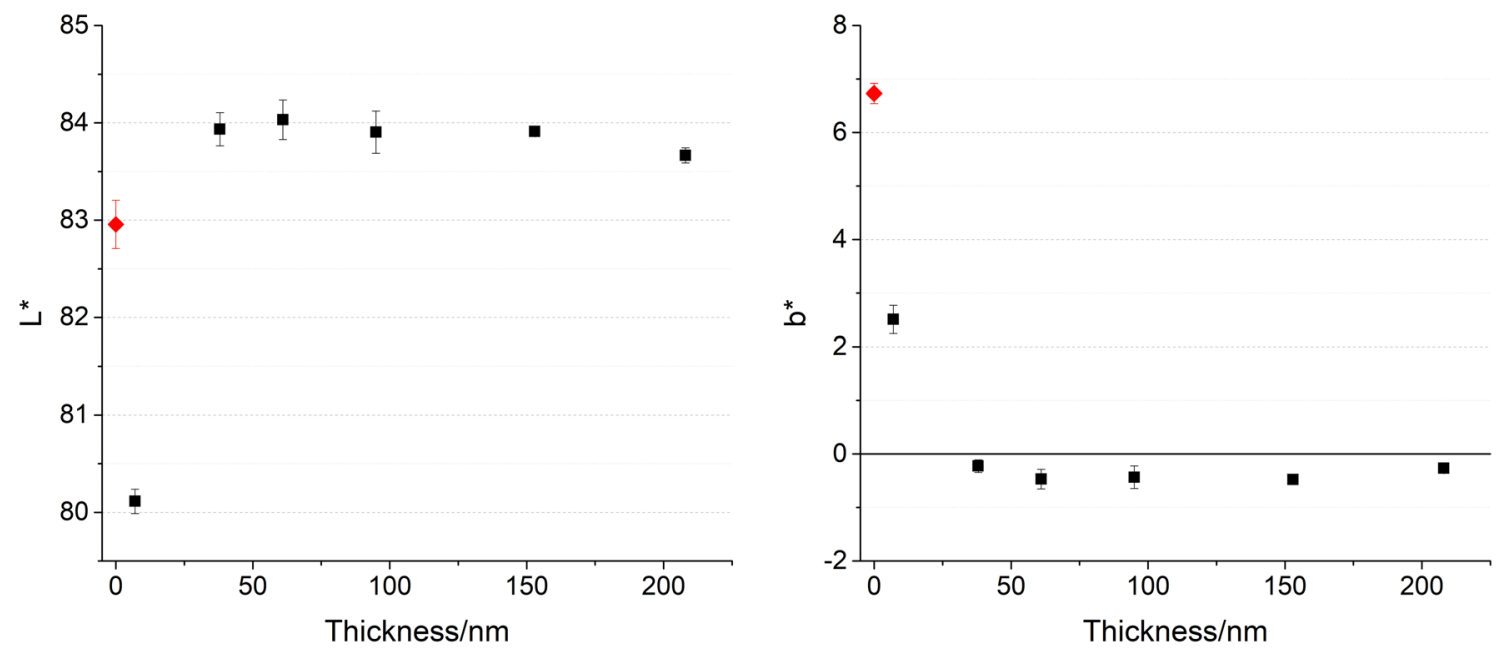

Fig. 6 Plots of the color values $L^{*}$ and $b^{*}$ versus the thickness of chromium layers electroplated at pulsed current with a peak current density of $5 \mathrm{~A} \mathrm{dm}^{-2}$, a frequency of $0.027 \mathrm{~Hz}$ and a duty cycle of $40 \%$. The red data points at a thickness of zero correspond to the bright nickel substrate

of the DC-plated samples, $L^{*}$ and $b^{*}$ were plotted versus thickness (Fig. 6). The standard deviation is comparable to the DC-plated samples. SEM images were taken at several stages (Fig. 7). The results for the bright nickel substrate are shown first, which correspond to a chromium thickness of zero. Since nickel has a strong yellowish color, the $b^{*}$ value is in the high positive range $(+6.7)$, while $L^{*}$ is in the same range as DC-plated chromium (83.0). The morphology of bright nickel is very fine-grained, but has a different texture than chromium (Fig. 7a).

After applying one pulse, about 5 to $10 \mathrm{~nm}$ of chromium is plated, shifting $b^{*}$ to lower values $(+2.5)$, while $L^{*}$ decreases (80.1). As the chromium thickness is very low, both the nickel substrate and the chromium top layer contribute to the overall optical appearance. Furthermore, the chromium layer might not be completely dense, so that part of the nickel lies still open. The morphology is very similar to bright nickel (Fig. 7b), as the structure of the nickel is just replicated by the chromium and the typical chromium morphology has not formed yet. After five pulses, corresponding to a thickness of $40 \mathrm{~nm}$, the $b^{*}$ is shifted to negative values, indicating a blueish color hue. $L^{*}$ is increased to 83.9, a lightness value that is even higher than the $L^{*}$ value of the DC-plated samples. A morphology has formed that is similar to the DC sample with the same thickness (Figs. 2a and $7 \mathrm{c}$, respectively). The porosity is likewise as low as for the samples plated under constant current. The grain size is about $40 \mathrm{~nm}$. If the number of pulses and thus the chromium thickness is further increased, $L^{*}$ and $b^{*}$ remain almost stable, while the morphology is changing (Fig. 7d). Optimum color values of $L^{*}=84.0$ and $b^{*}=-0.5$ could be achieved.

At 25 pulses, corresponding to a thickness $210 \mathrm{~nm}$, the grain size increased to values between 70 and $100 \mathrm{~nm}$
(Fig. 7e). Thus, surface morphology is still not fully independent from thickness. The color values are slightly shifted to $L^{*}=83.6$ and $b^{*}=-0.3$. However, $b^{*}$ is still in the negative range. A DC-plated sample with similar thickness, as can be seen in Fig. 1, shows color values of around $L=82.5$ and $b=+0.3$. The optical appearance was improved significantly by shifting the color hue from yellowish to blueish and increasing the lightness.

\subsection{Combination of DC and pulse plating}

As has been discussed above an improvement of the appearance can be accomplished by low-frequency pulse plating. However, the method is very time-consuming. Compared to a $\mathrm{DC}$ process, the plating time is prolonged by a factor of 2.5. To deposit a chromium layer with a thickness of approximately $220 \mathrm{~nm}$, about $6 \mathrm{~min}$ and $15 \mathrm{~s}$ are needed at constant current and 25 pulses (15 min and $37.5 \mathrm{~s}$ ) at pulsed current (Fig. 8a, b). One way to reduce the total plating time is the combination of DC and pulse plating (Fig. 8c). First, 5 min of constant current with a current density of $5 \mathrm{~A} \mathrm{dm}^{-2}$ are applied to deposit about $180 \mathrm{~nm}$ of chromium, corresponding to $80 \%$ of the final layer thickness. Five pulses ( $3 \mathrm{~min}$ and $7.5 \mathrm{~s}$ ) of low-frequency pulse plating at the parameters mentioned above were added subsequently.

In this way, five thin sub-layers with a fine-grained structure are plated on a thick base layer. The total plating time was about $8 \mathrm{~min}$. Color values of $L^{*}=83.7$ and $b^{*}=-0.5$ are achieved by this method. The morphology of the deposit (Fig. 9) is very similar to the surface structure of the sample plated with 25 pulses of low-frequency pulse plating (Fig. 7e). The grain size (70 to $100 \mathrm{~nm}$ ) and the porosity are the same. The average thickness of both samples is close to 

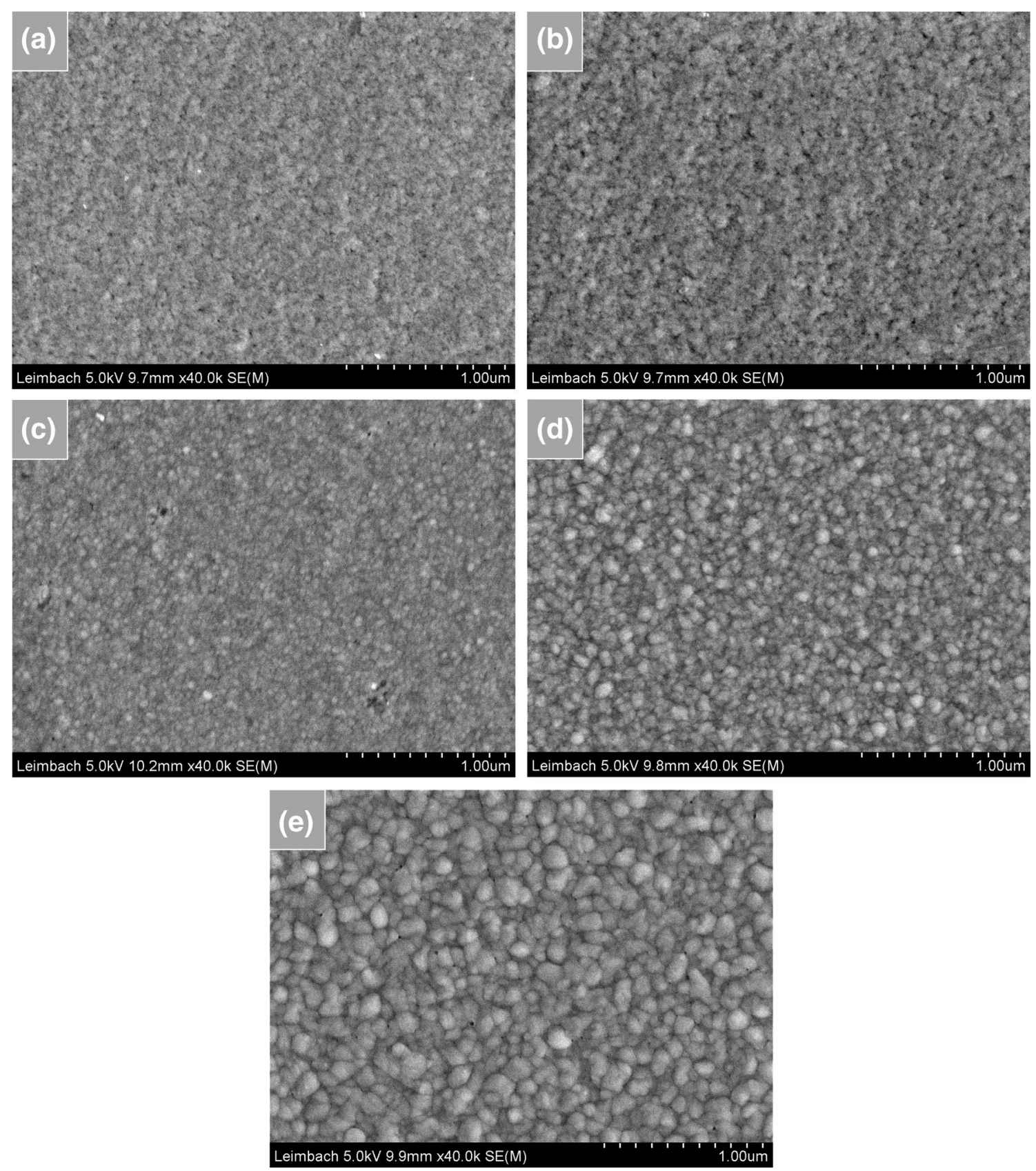

Fig. 7 SEM images of a bright nickel layer and chromium layers electroplated at pulsed current with a peak current density of $5 \mathrm{~A} \mathrm{dm}^{-2}$, a frequency of $0.027 \mathrm{~Hz}$ and a duty cycle of $40 \%$. a Bright nickel with- out chromium, b one pulse applied (5 to $10 \mathrm{~nm}$ of chromium), c five pulses $(40 \mathrm{~nm}), \mathbf{d} 15$ pulses $(95 \mathrm{~nm})$ and e 25 pulses $(210 \mathrm{~nm})$ 

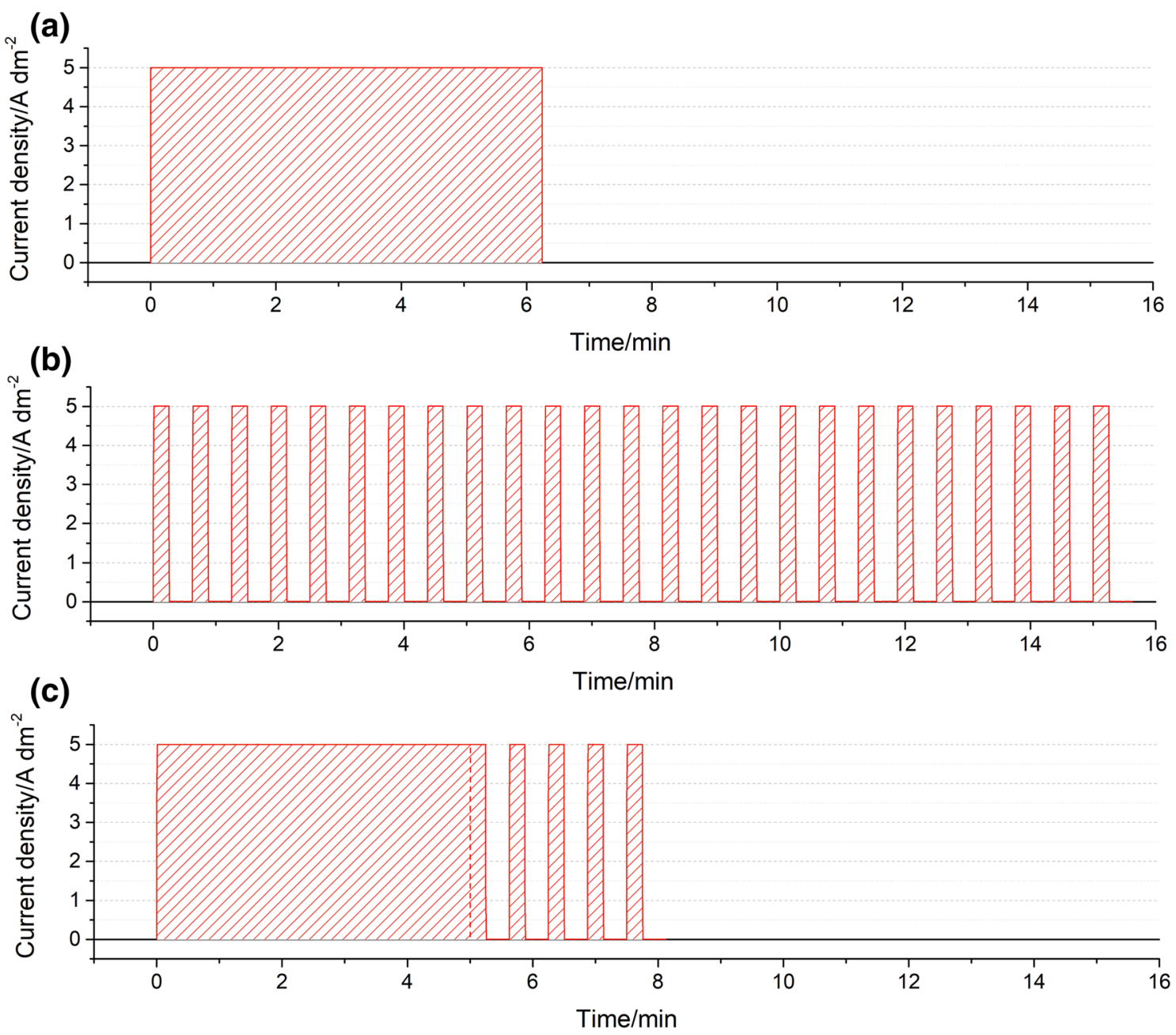

Fig. 8 Current regimes for the electrodeposition of approx. $220 \mathrm{~nm}$ of chromium at a constant current, b pulsed current with a frequency of $0.027 \mathrm{~Hz}$ and a duty cycle of $40 \%$ and $\mathbf{c}$ a combination of both

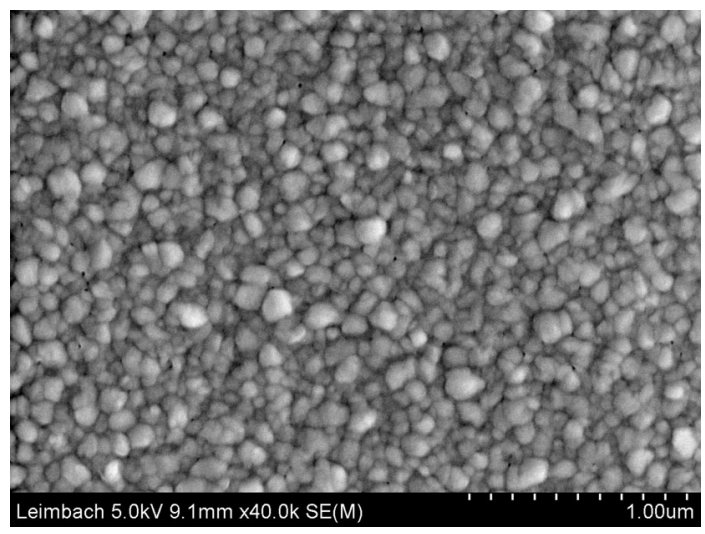

Fig. 9 SEM images of a chromium layer electroplated in a combined process of constant current at a current density of $5 \mathrm{~A} / \mathrm{dm}^{2}$ and pulsed current with a peak current density of $5 \mathrm{~A} \mathrm{dm}^{-2}$, a frequency of $0.027 \mathrm{~Hz}$ and a duty cycle of $40 \%$. The current regime is displayed in Fig. 8c each other, too. About $220 \mathrm{~nm}$ of chromium was deposited by the combined pulse regime and $210 \mathrm{~nm}$ by 25 cycles of pulse plating. Thus, similar results were achieved by both using a combination of DC and pulse plating and by applying pulse plating only.

\section{Conclusions}

Pulse plating has been applied to deposit chromium from a trivalent chromium sulfate electrolyte with a tailored optical appearance. By applying a constant current, the surface grain size increases during metal deposition, leading to a color shift from blueish to yellowish. Low-frequency pulse plating with a pulse current density of $5 \mathrm{~A} \mathrm{dm}^{-2}$, an on-time of $15 \mathrm{~s}$ and an off-time of $22.5 \mathrm{~s}$ was beneficial for the layer quality. In this way, chromium layers with a blueish color 
hue and high brightness could be produced with thicknesses of more than $200 \mathrm{~nm}$. Optimum color values of $L^{*}=84.0$ and $b^{*}=-0.5$ were achieved after 9 min and $22.5 \mathrm{~s}(15$ cycles) of pulse plating. A combination of constant and pulsed current gives similar results in morphology and color values as using pulsed current only, but at half of the process time. Future work will aim at a detailed investigation of pulse parameters and the microstructure of the layers.

Acknowledgements Open Access funding provided by Projekt DEAL. This research was done within the framework of a collaboration between Technische Universität Ilmenau and Hansgrohe SE. Kiesow Dr. Brinkmann $\mathrm{GmbH} \& \mathrm{Co}$. KG is kindly acknowledged for providing the nickel and chromium electrolytes.

Open Access This article is licensed under a Creative Commons Attribution 4.0 International License, which permits use, sharing, adaptation, distribution and reproduction in any medium or format, as long as you give appropriate credit to the original author(s) and the source, provide a link to the Creative Commons licence, and indicate if changes were made. The images or other third party material in this article are included in the article's Creative Commons licence, unless indicated otherwise in a credit line to the material. If material is not included in the article's Creative Commons licence and your intended use is not permitted by statutory regulation or exceeds the permitted use, you will need to obtain permission directly from the copyright holder. To view a copy of this licence, visit http://creativecommons.org/licenses/by/4.0/.

\section{References}

1. Lindsay JH (1997) Decorative and hard chromium plating. Plat Surf Finish 84(8):50-51

2. Snyder DL (2012) Decorative chromium plating basics. Met Finish 110(2):14-21

3. Handy SL, Oduoza CF, Pearson T (2006) Theoretical aspects of electrodeposition of decorative chromium from trivalent electrolytes and corrosion rate study of different nickel/chromium coatings. Trans IMF 84(6):300-308. https://doi.org/10.1179/17459 $1906 \times 162946$

4. European Chemicals Agency Authorisation List, EC No. 215607-8, 231-801-5, 231-889-5, 231-906-6, 232-140-5, 232143-1, 234-190-3, 236-881-5

5. Gupta VK, Shrivastava AK, Jain N (2001) Biosorption of chromium(VI) from aqueous solutions by green algae Spirogyra species. Water Res 35(17):4079-4085. https://doi.org/10.1016/ S0043-1354(01)00138-5

6. Gianelos L (1979) Production experience with trivalent chromium plating solutions. Plat Surf Finish 66(5):56-60

7. Del Pianta D, Frayret J, Gleyzes C, Cugnet C, Dupin JC, Le Hecho I (2018) Determination of the chromium(III) reduction mechanism during chromium electroplating. Electrochim Acta 284:234-241. https://doi.org/10.1016/j.electacta.2018.07.114

8. Katirci R (2016) A chrome coating from a trivalent chromium bath containing extremely low concentration of $\mathrm{Cr}^{3+}$ ions. Int J Surf Sci Eng 10(1):73-85

9. Zeng ZX, Liang AM, Zhang JY (2009) A review of recent patents on trivalent chromium plating. Recent Pat Mater Sci 2(1):50-57

10. Snyder DL (2003) Distinguishing trivalent chromium deposits by color. Plat Surf Finish 90(11):34-39
11. Sheasha Y, Yücel D, Kibler LA, Knape M, Holl S, Henne S, Heitmüller S, Jacob T (2017) Potentiodynamic chromium deposition from trivalent and hexavalent systems on glassy carbon electrodes: initial stages and mechanistic insights. ChemElectroChem 4(6):1390-1394. https://doi.org/10.1002/celc.201700175

12. Leimbach M, Tschaar C, Zapf D, Kurniawan M, Schmidt U, Bund A (2019) Relation between color and surface morphology of electrodeposited chromium for decorative applications. J Electrochem Soc 166(6):D205-D211. https://doi.org/10.1149/2.0871906jes

13. Hansal WEG, Roy S (2012) Pulse plating. Eugen G. Leuze Verlag KG, Bad Saulgau, pp 72-82. https://doi.org/10.12850/97838 74803236.004

14. Chin DT, Zhang HB (1986) A study of pulse pulse plating of chromium. Electrochim Acta 31(3):299-306. https://doi. org/10.1016/0013-4686(86)80082-2

15. Leisner P, Bechnielsen G, Moller P (1993) Current efficiency and crystallization mechanism in pulse plating of hard chromium. $\mathrm{J}$ Appl Electrochem 23(12):1232-1236

16. Chang JH, Hsu FY, Liao MJ, Huang CA (2007) A study of directand pulse-current chromium electroplating on rotating cylinder electrode (RCE). Appl Surf Sci 253(16):6829-6834. https://doi. org/10.1016/j.apsusc.2007.01.124

17. Tu ZM, Yang ZO, Zhang JH (1990) Pulse plating with a trivalent chromium plating bath. Plat Surf Finish 77(10):55-57

18. Mohan S, Saravanan G, Renganathan NG (2011) Comparison of chromium coatings and electrochemical behaviour with direct current and pulse current deposition in trivalent chromium formate urea bath as alternative to conventional $\mathrm{Cr}$ coatings. Surf Eng 27(10):775-783. https://doi.org/10.1179/174329408x32633 5

19. Danilov FI, Protsenko VS, Gordiienko VO, Baskevich AS, Artemchuk VV (2012) Electrodeposition of nanocrystalline chromiumcarbon alloys from electrolyte based on trivalent chromium sulfate using pulsed current. Prot Met Phys Chem 48(3):328-333. https ://doi.org/10.1134/S2070205112030057

20. Lozano-Morales A, Renz R, Fortman J, Taylor EJ (2007) Electrically mediated process for functinal and decorative trivalent chromium electroplating: an alternative to hexavalent chromium. ECS Trans 6(9):51-61. https://doi.org/10.1149/1.2790401

21. Protsenko VS, Danilov FI, Gordiienko VO, Baskevich AS, Artemchuk VV (2012) Improving hardness and tribological characteristics of nanocrystalline $\mathrm{Cr}-\mathrm{C}$ films obtained from $\mathrm{Cr}(\mathrm{III})$ plating bath using pulsed electrodeposition. Int J Refract Met H 31:281283. https://doi.org/10.1016/j.ijrmhm.2011.10.006

22. Saravanan G, Mohan S (2009) Corrosion behavior of $\mathrm{Cr}$ electrodeposited from $\mathrm{Cr}(\mathrm{VI})$ and $\mathrm{Cr}(\mathrm{III})$-baths using direct (DCD) and pulse electrodeposition (PED) techniques. Corros Sci 51(1):197-202. https://doi.org/10.1016/j.corsci.2008.10.005

23. Giovanardi R, Bozza A (2014) Effect of temperature on pulsed current chromium electrodeposition from $\mathrm{Cr}$ (III) aqueous solutions. Metall Ital 106(7-8):9-16

24. Brankovic SR (2019) Crack formation during electrodeposition and post-deposition aging of thin film coatings. NASF Surf Technol White Papers 83(5):8-16

25. Hall TD, Xu J, Radhakrishnan R, Snyder ST, Taylor EJ, Inman ME, Feathers M, Johnson M (2019) Improved wear performance of REACH compliant trivalent chromium plating process. Paper presented at SUR/FIN, Rosemont, IL

26. Kiesow DR, Brinkmann GmbH \& Co. KG (2017) Data Sheet ORION 4000 Bright Nickel Electrolyte

27. Kiesow DR, Brinkmann GmbH \& Co. KG (2015) Data Sheet SAPHIR 2000 Bright Chromium Electrolyte 
28. Leimbach M, Tschaar C, Schmidt U, Bund A (2018) Electrochemical characterization of chromium deposition from trivalent solutions for decorative applications by EQCM and near-surface pH measurements. Electrochim Acta 270:104-109. https://doi. org/10.1016/j.electacta.2018.03.011

29. CIE Technical Report No. 15 (2004) Colorimetry, 3rd ed
30. ASTM E 308 - 01, Standard Practice for Computing the Colors of Objects by Using the CIE System

Publisher's Note Springer Nature remains neutral with regard to jurisdictional claims in published maps and institutional affiliations.

\section{Affiliations}

\section{Martin Leimbach ${ }^{1} \oplus \cdot$ Christoph Tschaar $^{1,2} \cdot$ Udo Schmidt $^{1} \cdot$ Andreas Bund $^{1} \oplus$}

1 Electrochemistry and Electroplating Group, Technische Universität Ilmenau, Gustav-Kirchhoff-Straße 6, 98693 Ilmenau, Germany

2 Hansgrohe SE, Auestraße 5-9, 77761 Schiltach, Germany 